\title{
ASSESSMENT OF GLACIER VOLUME CHANGE USING ASTER- BASED SURFACE MATCHING OF HISTORICAL PHOTOGRAPHY
}

\author{
Pauline E. Miller, Matthias Kunz, Jon P. Mills, Matt A. King, Tavi Murray, Timothy D. James and \\ Stuart H. Marsh
}

\begin{abstract}
Glaciated regions are known to be particularly sensitive to climate change. Historical archives of glacier volume change are important as they provide context for present-day changes. Although photogrammetric archives exist for many regions, their usefulness is often limited by a lack of contemporary ground control. High quality digital elevation models (DEMs) underpin a range of change analysis activities. This paper presents a cost-effective solution which utilizes ASTER DEMs as control for scaling and orientation of archival datasets. Instead of relying upon ground control points, a robust surface matching algorithm is employed to automatically determine the transformation required to register two overlapping DEMs.

Through application to the Slakbreen glacier system in Svalbard, Norway, the strategy is assessed by firstly matching an ASTER DEM to a fixed lidar reference surface. This demonstrates that ASTER DEMs are effectively correct in scale, supporting their use as a control surface. The second stage of the research implements this by matching an aerial photogrammetric DEM to an ASTER reference surface. Resultant volumetric and annual elevation change rates are compared to those derived from lidar data, which is considered here as a truth dataset. ASTERbased matching produced a mean annual elevation change rate of $-4.12 \mathrm{ma}^{-1}$, compared to a value of $-4.11 \mathrm{ma}^{-1}$ derived from lidar data. In volumetric terms, this equates to a difference of $0.6 \%$. A major advantage of this approach is the near-global coverage offered by ASTER data, and the opportunity this presents for remote, glacial change analysis over regional extents.
\end{abstract}

Index Terms-Remote sensing, Geodesy, Terrain mapping

Manuscript received on $22^{\text {nd }}$ September, 2008.

Pauline E. Miller, Matthias Kunz, Jon P. Mills and Matt A. King are with the School of Civil Engineering and Geosciences, Newcastle University, Newcastle upon Tyne. NE1 7RU. UK (phone: +44-191-222-5268; fax:+44-191-222-6502; email: p.e.miller@ncl.ac.uk; matthias.kunz@ncl.ac.uk; j.p.mills@ncl.ac.uk; m.a.king@ncl.ac.uk).

Tavi Murray and Timothy D. James are with the Department of Geography, Swansea University, Swansea. SA2 8PP. UK (email: t.murray@,swansea.ac.uk; t.d.james@,swansea.ac.uk).

Stuart H. Marsh is Head of Spatial Geoscience Technologies at the British Geological Survey, Keyworth, Nottingham. NG12 5GG. UK (email : shm@bgs.ac.uk).

\section{INTRODUCTION}

$\mathrm{G}$ lacier ice loss has been the dominant mass contributor to sea level change during the $20^{\text {th }} \mathrm{C}$ [1]. However, the presently available record for glacier mass change is far from complete, both in terms of the number of glaciers sampled and the available time series extent and sampling frequency. A number of national and international projects are underway in order to recover the missing information from historical archives (e.g, [2]). One important step toward assessing glacier mass change (which affects sea level) is a more complete understanding of glacier volume change.

Historical archives of aerial photography are now recognised as being an extremely valuable source of this information. However, one of the greatest barriers to reliable change detection and analysis is the effective registration of multi-sensor, multi-temporal DEMs to a common reference frame. This is an essential task, as registration errors between DEMs will propagate into estimates of elevation or volume change, rendering any subsequent results or conclusions unreliable. However, successful registration of DEMs in remote and hostile environments is not a straightforward process, with the complicating step that comparison with modern-day elevations requires the establishment of often expensive ground-control in order to scale the stereoscopic images. In many cases this information was never collected or is not available in a reference frame consistent with modern techniques. Conventional approaches require the use of identifiable ground control points. However, a variation on this is the technique proposed by [3], whereby ground-control points are manually extracted from modern-day digital elevation models (DEMs) based on lidar data controlled by Global Positioning System (GPS) data. An alternative method is presented by [4], who orient archival photography through the use of control points derived from modern aerial photography which has been accurately controlled via direct GPS positioning of the camera stations. However, both these approaches can be troublesome in the case of relatively featureless glaciated terrain, and the costs and time associated with such exercises are often prohibitive. 
Where suitably well-controlled historical DEMs are available, these are now routinely differenced with DEMs from the Shuttle Radar Topography Mission (SRTM), Advanced Spaceborne Thermal Emission and Reflection Radiometer (ASTER) or airborne lidar data in order to compute ice volume change (e.g. [5]-[8], amongst others). ASTER is particularly attractive as it offers near-global coverage at relatively high spatial resolution and accuracy and with low cost. Regardless of the modern-day data source, however, care is needed when differencing with historical DEMs since mission-specific biases may exist (e.g. [9]) even after accounting for differences in reference frame and/or reference ellipsoid. Differences in scale, translation and rotation between the different data sets are assumed negligible and hence are not typically taken into account; any errors of this kind will produce systematic errors in glacier volume change. Clearly what would be ideal, is an approach that took advantage of the spatial coverage and low cost of ASTER DEMs, but included the rigour of [3] and [4] applied in an automated fashion.

This paper proposes a solution which employs an ASTER DEM as a control surface for registration of archival DEMs, facilitating subsequent glacial change analysis. This approach dispenses with the requirement for conventional ground control points, and instead employs a least squares-based surface matching algorithm. The first section of the paper assesses the quality of the ASTER DEM, and illustrates the viability of utilising ASTER as a source of control for scaling of archival photogrammetric DEMs. The second section implements the ASTER-based control approach, assessing the quality of the results through analysis of glacial volumetric change. In both stages of the experiment, a lidar DEM of superior quality is used to assess the accuracy of the ASTERbased results. This strategy is applied to part of the Slakbreen glacier system on Spitsbergen, Svalbard.

\section{Study AREA AND DATASETS}

\section{A. Slakbreen Study Area}

The Slakbreen study area (Fig. 1) is located at $16^{\circ} 20^{\prime} \mathrm{E}$, $77^{\circ} 59^{\prime} \mathrm{N}$ on Spitsbergen, the largest island of the Svalbard archipelago, Norway. Svalbard lies at the northern reach of the warm North Atlantic Drift current, and consequently it is anticipated that this region may be relatively sensitive to the effects of climate change [10]. This is supported by a significant trend of $+0.16^{\circ} \mathrm{C}$ warming per decade between 1911 and 2004 [11]. As a result, the Svalbard archipelago is considered an important site for climate and glaciology studies.

Svalbard is comprised of mountainous and complex terrain, and the study area, which includes part of the Slakbreen glacier system, typifies this, with elevations ranging from $79 \mathrm{~m}$ to $1254 \mathrm{~m}$. The study area includes the front of the main Slakbreen glacier, and a smaller glacier to the south. As shown in Fig. 1, the glaciers are separated by a mountain range extending from east to west. The glaciers are composed of relatively gentle slopes, largely below $10^{\circ}$, whilst the mountain area incorporates slopes ranging from $25^{\circ}$ to $45^{\circ}$. As the terrain surface is primarily glaciated, the majority of geomorphologic change can be expected to occur as a result of glaciological processes and glacier melt. Tundra vegetation is dominant, and taller species such as shrubs and trees do not occur.

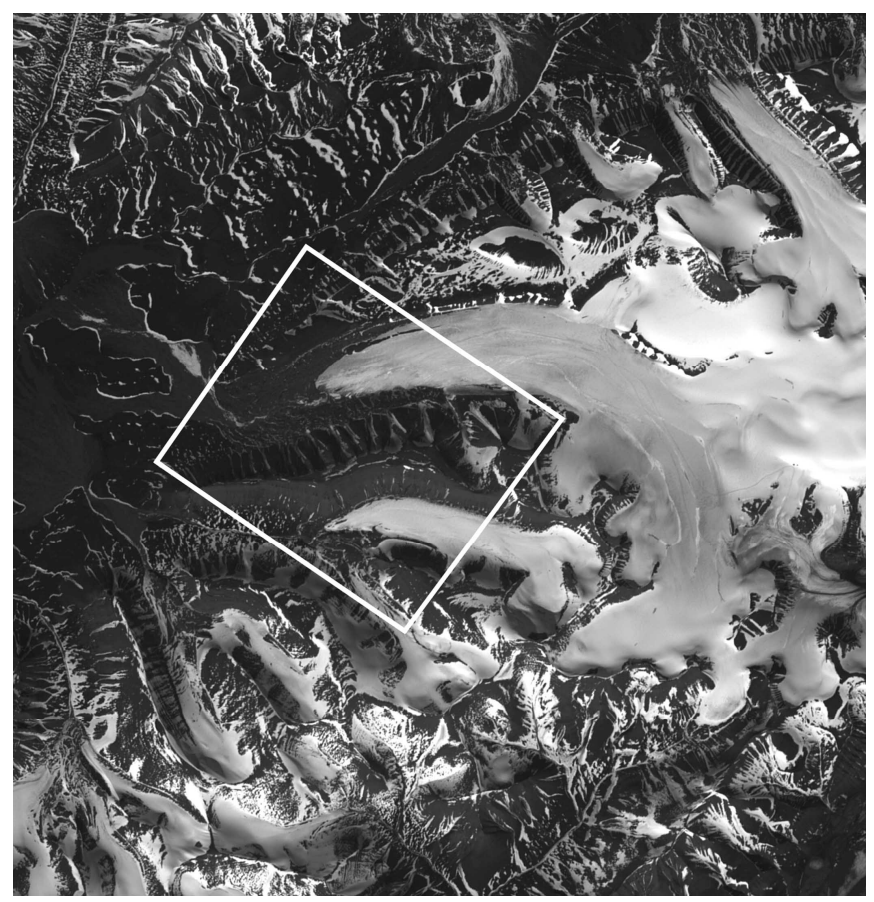

Fig. 1. Subset of ASTER scene (13-06-2002), highlighting the study area within the Slakbreen glacier system.

\section{B. Datasets \\ 1) ASTER Data}

The ASTER sensor, mounted on the TERRA satellite platform, provides multi-spectral imagery and derived DEMs of the Earth's surface for latitudes between $82^{\circ} \mathrm{N}$ and $82^{\circ} \mathrm{S}$. ASTER DEMs are available from the NASA-USGS Land Processes Distributed Active Archive Center (LP DAAC), where they are produced through an automated stereocorrelation method [12]. Users can also generate their own DEMs by ordering stereo images directly, as described by [13]. Production of ASTER DEMs is based on photogrammetric principles, and therefore image matching is a fundamental aspect. However, glaciated terrain can be susceptible to correlation difficulties, particularly in areas of snow cover, where image texture is poor [14], and this can have a detrimental effect on the quality of the resultant DEM. It is therefore important to fully assess image/DEM quality in this regard, prior to any analysis activities.

ASTER DEMs are relatively inexpensive compared to alternative techniques such as lidar or aerial photogrammetry, and ASTER provides good near-global coverage, with a revisit period of five days. ASTER DEMs offer a vertical accuracy of $\pm 7 \mathrm{~m}$ at best, but this varies greatly depending on the nature of 
the terrain, the quality of the imagery, and the processing strategy employed [13], [15]. ASTER data is well-suited to a range of environmental applications, and ASTER DEMs have been utilised in a number of recent studies relating to earth surface processes (e.g. [16]-[18]) and glaciological analysis [19]. However, for some forms of geomorphological analysis, the accuracy of the DEM product can be a limiting factor [16], and very little research has thus far focussed on investigating this aspect. In this study, an ASTER DEM scene from the $13^{\text {th }}$ June 2002 was obtained from LP DAAC. This DEM offers a spatial resolution of $30 \mathrm{~m}$, and an $\mathrm{RMSE}_{\mathrm{xyz}}$ of better than $25 \mathrm{~m}$ [20]. As illustrated in Fig. 1, the ASTER scene exhibits no cloud cover and presents near nadir-viewing.

\section{2) Lidar Data}

Lidar is an airborne laser ranging technique which is capable of producing dense and accurate digital topographic models [21]. The data are normally acquired from either a fixed or rotary wing aircraft, and georeferenced directly using an in-flight system which combines GPS and inertial measurement unit (IMU) measurements in order to determine aircraft position and orientation. As the technology and associated processing algorithms continue to mature, lidar is becoming increasingly applicable for a diversity of applications, including flood plain modelling, forestry, coastal monitoring, transport corridor mapping, city modelling, and bathymetric applications. As a direct sensing technique, lidar is unaffected by the correlation problems associated with image-based DEMs, and consequently, offers significant potential for monitoring of glaciated terrain [22].

The lidar dataset for the Slakbreen study area was acquired on the $8^{\text {th }}$ August 2003 by the UK Natural Environment Research Council's Airborne Research and Survey Facility (NERC ARSF). The data were acquired using an Optech ALTM 3033 instrument, mounted on a fixed wing aircraft. This sensor offers a specified vertical accuracy of better than $\pm 0.15 \mathrm{~m}$ from a flying height of $1000 \mathrm{~m}$ [23]. This error is dominated by GPS positioning errors, although these could be reduced by employing more sophisticated GPS analysis strategies [24]. In this study, the data were acquired from a flying height of $2800 \mathrm{~m}$. This suggests that the vertical accuracy may be poorer than the specified value of $\pm 0.15 \mathrm{~m}$. Despite this, the accuracy of the lidar DEM will remain an order of magnitude higher than the ASTER DEM. Planimetric accuracy is dependant on the quality of the GPS-IMU solution; previous experience with this system suggests that this is likely to be within $\pm 0.20 \mathrm{~m}$. The study area, which comprises $120 \mathrm{~km}^{2}$, was flown in nine strips, at a spatial resolution of approximately $2 \mathrm{~m}$. This resulted in over 46 million lidar points. The dataset consisted of first and last pulse returns, but due to the lack of surface vegetation, no difference existed between the two pulses, and so first pulse returns were discarded.

\section{3) Aerial Photography}

Aerial photography is an important resource for interpretation of landscape change. However, where metric photography is available, photogrammetric measurements can also be carried out, thus enabling quantitative analysis of change. As discussed in Section I, archival aerial photography is relatively abundant for many glaciated regions. Advances in digital photogrammetry over the last ten to fifteen years have resulted in highly automated, standardised workflows for photogrammetric DEM extraction. As a result, photogrammetry is now relatively accessible to non-experts, offering earth scientists improved opportunities for utilisation of archival photogrammetric datasets in change detection studies. However, while a number of scientists have exploited such opportunities (e.g. [25], [26]), the uptake is disproportionately low in comparison to the extensive archival collections which exist. As highlighted by [4], this is partly due to factors such as non-standard imagery, a lack of camera calibration information, and poor image quality. However, as discussed in Section I, one of the primary limitations relates to the difficulties associated with obtaining reliable ground control.

For purposes of validation, a relatively recent epoch of aerial photography was used in this study. This was acquired on the $8^{\text {th }}$ August 2003, contemporaneous to the lidar dataset. The imagery was flown at a scale of 1:16,000, and scanned at a resolution of $11 \mu \mathrm{m}$, resulting in a ground sample distance of $0.18 \mathrm{~m}$. The images were then processed in a BAE Systems Socet Set digital photogrammetric workstation [27] to extract a $10 \mathrm{~m}$ grid DEM for the Slakbreen study site.

\section{Methodology}

When integrating multiple datasets, registration to a common reference frame is of fundamental importance [28]. This is also a critical aspect of change detection analysis, as it is essential to ensure that differences due to registration error are minimised. However, the registration process is not always straightforward. Conventionally, common control points can be used to register multiple datasets in preparation for difference detection. However, in remote and challenging terrain, such as that found in the Slakbreen study area, establishing control points in the field can be both costly and logistically challenging. Furthermore, due to the relatively low spatial resolution of the ASTER data, and the 'blind' nature of lidar (in the sense that terrain data is captured in an indiscriminate manner, and specific features are not directly recorded) it can be difficult to improve registration through the use of control points. In addition, in the case of archival aerial photography, landscape change can severely hamper identification of control points in the field. This paper presents a solution to the basic registration problem, which is independent of the data collection technique, and the spatial resolution of the source DEMs.

\section{A. Robust Surface Matching}

Surface matching offers a software-based solution to dataset 
registration, removing the requirement for specific ground control points, and instead deriving control from the geometry of the DEM surfaces. In this research, a robust least squaresbased surface matching algorithm was used [29]. In general terms, the goal of surface matching is to recover the optimum transformation which aligns a poorly-controlled 'floating' surface to a well-controlled fixed reference surface. However, essentially surface matching can be considered as a tool which enables multiple overlapping datasets to be transformed to a common reference system, as defined by the reference DEM. The algorithm implemented here is based on a standard 3D conformal coordinate transformation, which enables conversion from one three-dimensional coordinate system to another, by means of three rotations $(\omega, \varphi, \kappa)$, three translations $(T x, T y, T z)$ and a scale factor $(s)$ [30].

Each DEM point on one surface can be considered to provide control information, and the algorithm attempts to minimise the vertical difference between a point on the matching surface, and a corresponding surface patch on the reference surface [31]. In standard least squares fashion, these differences are minimised globally across the surfaces, and the procedure is iterated until convergence is achieved. A key advantage of this approach is its inherent capacity for difference detection; the final post-match least squares residuals correspond to vertical differences between the two surfaces, which may arise due to terrain change over time. An overview of the basic algorithm is provided by [31] and [32], and [33] describe the implementation of this for monitoring of dynamic coastal terrain. The mountainous terrain of the Slakbreen study site is well-suited to surface matching, offering strong surface gradients, which help to constrain the matching solution.

The basic surface matching algorithm has been further developed in order to increase robustness to outlying observations. Due to differing acquisition techniques and temporal differences between collection epochs, DEM surfaces will never be identical. Moreover, in dynamic environments, such as that under study here, there is potential for more significant differences to arise as a result of processes such as glacier melt. The introduction of local discrepancies between the surfaces will influence the estimation of the transformation parameters, and where the effects are significant, conventional least squares approaches may fail, or may converge to an erroneous solution [34]. To overcome this, a weighting function based on a maximum likelihood estimator (M-estimator) was embedded in the software. The M-estimator analyses the least squares residuals following each iteration, and assigns weights to individual observations on the basis of the magnitude of their associated residuals. This enables those observations (individual DEM points) which produce large residual values to be automatically down-weighted accordingly [35]. Thus, the influence of outlying points, or regions of surface difference, can be mitigated and a more accurate solution is likely to be achieved. Similar approaches, based on the incorporation of robust estimation functions, have been shown to produce good results with experimental datasets [34], [36]. It is beyond the scope of this paper to provide a detailed account of the algorithm utilised here. Full details can be found in [29] and [37], where robust surface matching is implemented for coastal geohazard monitoring, demonstrating the improved accuracy of the robust algorithm over the basic version.

\section{B. Data Preparation}

The region corresponding to the study area (Fig. 1) was clipped from the source DEMs. Prior to matching, the lidar dataset was thinned using TerraSolid's TerraScan software [38]. This was necessary in order to avoid excessively long processing at the matching stage. In the future, computational efficiencies are expected and, for very large regions, computational cluster technologies could be employed. The original resolution of the ASTER and photogrammetric DEMs ( $30 \mathrm{~m}$ and $10 \mathrm{~m}$ respectively) was preserved. The datasets were referenced to UTM Zone 33 North.

After matching, the final transformation solution can be applied to the full resolution dataset if the matching DEM was thinned beforehand (although this was not the case here). LSS terrain modelling software [39] was used in order to calculate elevation differences between the DEM surfaces before and after matching. This enables elevation differences to be determined at every point on both surfaces. These values can then be output for further statistical analysis. For visualisation of the elevation differences and volumetric change analysis, ArcGIS software [40] was used.

\section{RESUlTS}

\section{A. Part I: ASTER Accuracy Assessment}

The first phase of the experiment involved establishing the accuracy of the ASTER DEM. Given the superior quality of the lidar DEM, this was designated as the reference surface, and the ASTER DEM was matched to this. The resultant transformation solution is presented in Table I. This shows that while the rotation parameters are relatively small, the translations are of a much larger magnitude, suggesting that the ASTER DEM may have contained systematic errors in plan and height. This is supported by visual inspection of the datasets, as illustrated in Fig. 2, which shows a typical crosssection through the DEMs, before (Fig. 2A) and after (Fig. 2B) matching. Simple DEM differencing would clearly produce erroneous volume change estimates.

The results suggest that robust surface matching has markedly improved the absolute accuracy of the ASTER DEM, through registration to the lidar DEM. Modifications to the scale parameter were relatively minor (Table I). Crucially, this shows that while the absolute accuracy of the ASTER DEM may be poor, the product is relatively stable in scale. The ramifications of this will be discussed below. 
TABLE I

TRANSFORMATION SOLUTION FOR ASTER TO LIDAR MATCHING

\begin{tabular}{cr}
\hline \hline Parameter & Value \\
\hline$\omega^{\circ}$ & 0.01796 \\
$\varphi^{\circ}$ & -0.01766 \\
$\kappa^{\circ}$ & -0.03622 \\
$T x(\mathrm{~m})$ & -30.528 \\
$T y(\mathrm{~m})$ & 30.002 \\
$T z(\mathrm{~m})$ & 33.496 \\
$s$ & 1.00205 \\
\hline
\end{tabular}

No. Iterations

19

In order to further assess the quality of the matching solution, the pre- and post-match elevation differences between the ASTER and lidar surfaces were analysed, with results as presented in Table II. On average, the more recent lidar surface lies nearly $38 \mathrm{~m}$ above the ASTER DEM prior to matching. This is a highly unlikely scenario, even if no melting or erosion occurred between 2002 and 2003, and lends further support to the presence of systematic error in the ASTER DEM. The post-match elevation difference statistics (Table II) strongly suggest that the accuracy of the ASTER DEM has been improved through surface matching. The mean difference between the surfaces is close to zero, and the RMSE value is five times better than the pre-match value. This post-match RMSE of $7.629 \mathrm{~m}$ is due to a combination of differences arising due to terrain change, the differing resolutions of the ASTER and lidar surfaces and random errors in each of the techniques. The mean post-match difference between the surfaces remains positive $(0.224 \pm 7.626 \mathrm{~m})$, and visual inspection of the post-match surface differences suggests that almost equal erosion (or melt) and deposition (or accumulation) has occurred over the 14 month period.
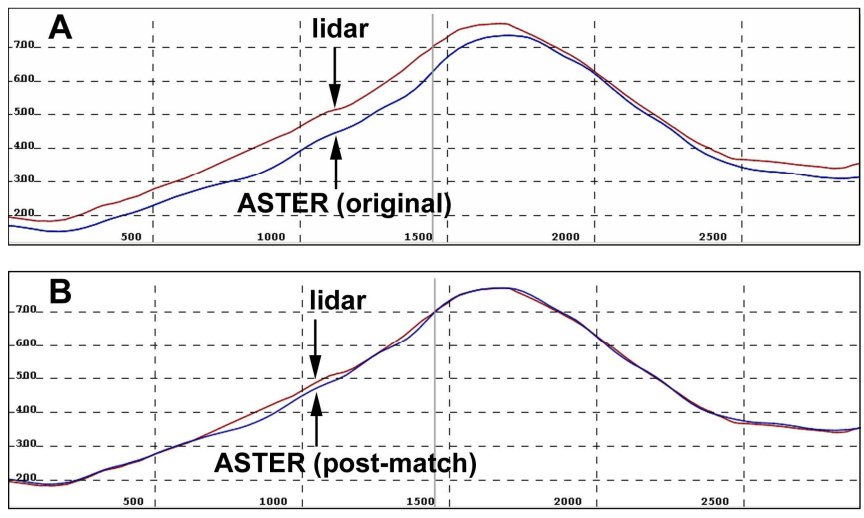

Fig. 2. Cross-section through DEMs (A) before and (B) after matching. Units are in metres.
TABLE II

PRE- AND POST-MATCH LIDAR-ASTER ELEVATION DIFFERENCE STATISTICS

\begin{tabular}{rrr}
\hline $\begin{array}{c}\text { Elevation Difference } \\
\text { Statistics }\end{array}$ & Pre-match & Post-match \\
\hline Mean (m) & 37.770 & 0.224 \\
Standard Deviation (m) & 13.640 & 7.626 \\
RMSE (m) & 40.158 & 7.629 \\
Maximum (m) & 110.611 & 46.458 \\
Minimum (m) & -22.657 & -43.945 \\
\hline \hline
\end{tabular}

\section{B. Part II: Multi-temporal Change Assessment}

\section{1) ASTER-based Surface Matching}

For the majority of glacier regions, lidar data will be unavailable, due to the relative scarcity and limited coverage of this data source. Crucially however, the results presented in Section IV, Part A demonstrate the scale stability of the ASTER DEM. This is highly relevant in the context of glaciology, where the most valuable aspect of change analysis relates to volumetric change, and measurements derived from this. Volumetric change remains constant irrespective of the absolute orientation of the surfaces, instead being reliant on the correct relative orientation and scaling of the surfaces. This would suggest that ASTER DEMs may be capable of providing a control surface for registration and scaling of aerial photogrammetric DEMs.

In order to explore this theory, matching was carried out using the photogrammetric DEM introduced in Section II. This $10 \mathrm{~m}$ DEM had been derived from imagery acquired at the same time as the 2003 lidar data, and consequently, the photogrammetric and lidar DEMs can be considered as being near-identical, although minor differences will exist due to the differing acquisition techniques and spatial resolutions. The photogrammetric surface had been oriented using pseudocontrol points, which were extracted directly from the lidar dataset. This satisfied the requirement that the surfaces be approximately aligned prior to matching, which is essential to ensure that good approximations are supplied for the unknown transformation parameters.

Three separate matches were carried out. The photogrammetric DEM was firstly matched to the lidar DEM. Following this, the raw photogrammetric DEM was then matched to the original ASTER dataset, and then the ASTER DEM was matched to the lidar DEM. In all three cases, the glacier regions were masked out of the matching surfaces. This was done in order to exclude these large, dynamic bodies, thus minimising potential for erroneous inter-epoch surface change. The robust matching software is designed to mitigate the impact of such differences, and as discussed in Section III, has previously been shown to be effective in doing so. However, in the absence of check point data, it was essential to optimise the conditions which contribute to a successful match, as the experiment hinges on ensuring that the photogrammetric-to- 
lidar match is reliable. The three matching solutions are detailed in Table III.

TABLE III

TRANSFORMATION SOLUTIONS FOR ASTER-BASED MATCHING ASSESSMENT

\begin{tabular}{crrr}
\hline Parameter & $\begin{array}{c}\text { (i) Photo to } \\
\text { lidar }\end{array}$ & $\begin{array}{c}\text { (ii) Photo to } \\
\text { ASTER }\end{array}$ & $\begin{array}{c}\text { (iii) ASTER } \\
\text { to lidar }\end{array}$ \\
\hline$\omega^{\circ}$ & 0.00040 & 0.00196 & 0.00325 \\
$\varphi^{\circ}$ & -0.00085 & 0.00567 & -0.01116 \\
$\kappa^{\circ}$ & -0.00200 & -0.03721 & 0.01205 \\
$T x(\mathrm{~m})$ & 0.350 & 29.057 & -27.631 \\
$T y(\mathrm{~m})$ & 0.122 & -29.922 & 29.993 \\
$T z(\mathrm{~m})$ & 0.079 & -34.064 & 34.715 \\
$s$ & 0.99990 & 0.99720 & 1.00180 \\
\hline Iterations & 6 & 20 & 16 \\
\hline \hline
\end{tabular}

Relatively minor transformations were required in order to match the photogrammetric DEM to the lidar DEM, and the solution was obtained relatively quickly, after only 6 iterations (Table III (i)). These results confirm the assumption that the photogrammetric and lidar surfaces are near-identical, thus supporting the use of the lidar surface in validating the results of the photogrammetric-to-ASTER matching. Crucially, the parameter solutions for the ASTER-to-lidar match (Table III (iii)) are similar to those obtained in Part I of this section, where the complete surfaces were utilised in matching (Table I). Although some minor differences do exist, experience has shown that slightly different parameter combinations can often result in near-identical solutions - an observation supported by [41]. This suggests that the robust matching algorithm, as employed over the complete surface in Part I, has been effective in mitigating the effects of any change over the glacier areas. The results of the photogrammetric-to-ASTER matching (Table III (ii)) and ASTER-to-lidar matching (Table III (iii)) are broadly similar, but in reverse. This is particularly evident through inspection of the translation values, and provides further confirmation that the photogrammetric and lidar DEMs were initially in good agreement. The relatively minor scale modification required to match the photogrammetric DEM to the ASTER DEM confirms that the ASTER DEM supplies a relatively stable basis for scaling of photogrammetric DEMs. Consequently, this would suggest that the strategy presented here is a valid approach for reliable determination of volumetric change in glaciated terrain. This is investigated further in the following section, which utilises the results of matches (ii) and (iii) in order to evaluate the success of this approach.
Fig. 3 shows the elevation differences between the ASTER DEM and the matched photogrammetric DEM. The surfaces display marked differences over a period of a little more than one year. From visual inspection, the largest changes occur over the mountain slopes. From a geomorphological perspective, such a pattern is possible, and there is some evidence of eroded material deposited at the foot of the mountains. However, the magnitude of these changes (up to $60 \mathrm{~m}$ in places) may be exacerbated by the differing spatial resolutions of the ASTER and lidar DEMs, especially over steep terrain. Even more significant though, is the influence of steep slopes combined with dark shadows, which will have degraded the quality of image matching and subsequent DEM production in the case of both the ASTER and photogrammetric DEMs in these areas. This represents an inherent limitation of image-based DEM creation. Over the highlighted glacier front, primarily negative change has occurred, suggesting glacier melt.

The quality of the photogrammetric-to-ASTER match was initially evaluated through analysis of the resultant surface elevation differences. A number of areas, away from the glaciers and mountain slopes, were selected on the basis that they were assumed to have remained stable over the period of study. Under such circumstances, there should be no significant differences between the surfaces at these locations. Analysis of these areas indicated that the matched surface was precise (in relation to the LiDAR surface) to approximately $\pm 3 \mathrm{~m}$ on a point-by-point basis. This discrepancy is likely to be mainly due to the differing spatial resolutions of the input datasets (10 $\mathrm{m}$ for the photogrammetric DEM, compared to $30 \mathrm{~m}$ for the ASTER dataset), and would therefore reduce with spatial averaging.

\section{2) Glacier Change Results}

The most effective means of assessing the success of the ASTER-based matching strategy is to compare volumetric differences between the photogrammetric-to-ASTER match, and the ASTER-to-lidar match, in both cases corresponding to change between June 2002 and August 2003. The latter can be considered as providing the most accurate solution, akin to a 'control' dataset. With modern GIS systems, computation of volumetric change is a relatively straightforward process. However, there are several factors which must be considered if representative mass change results are to be achieved in glaciology - for instance, the difference between the density of snow or ice is a factor of $\sim 3$. In this paper, a relatively straightforward approach is adopted, in order to concentrate solely on evaluating the potential of the ASTER-based matching strategy for volume change assessment. 


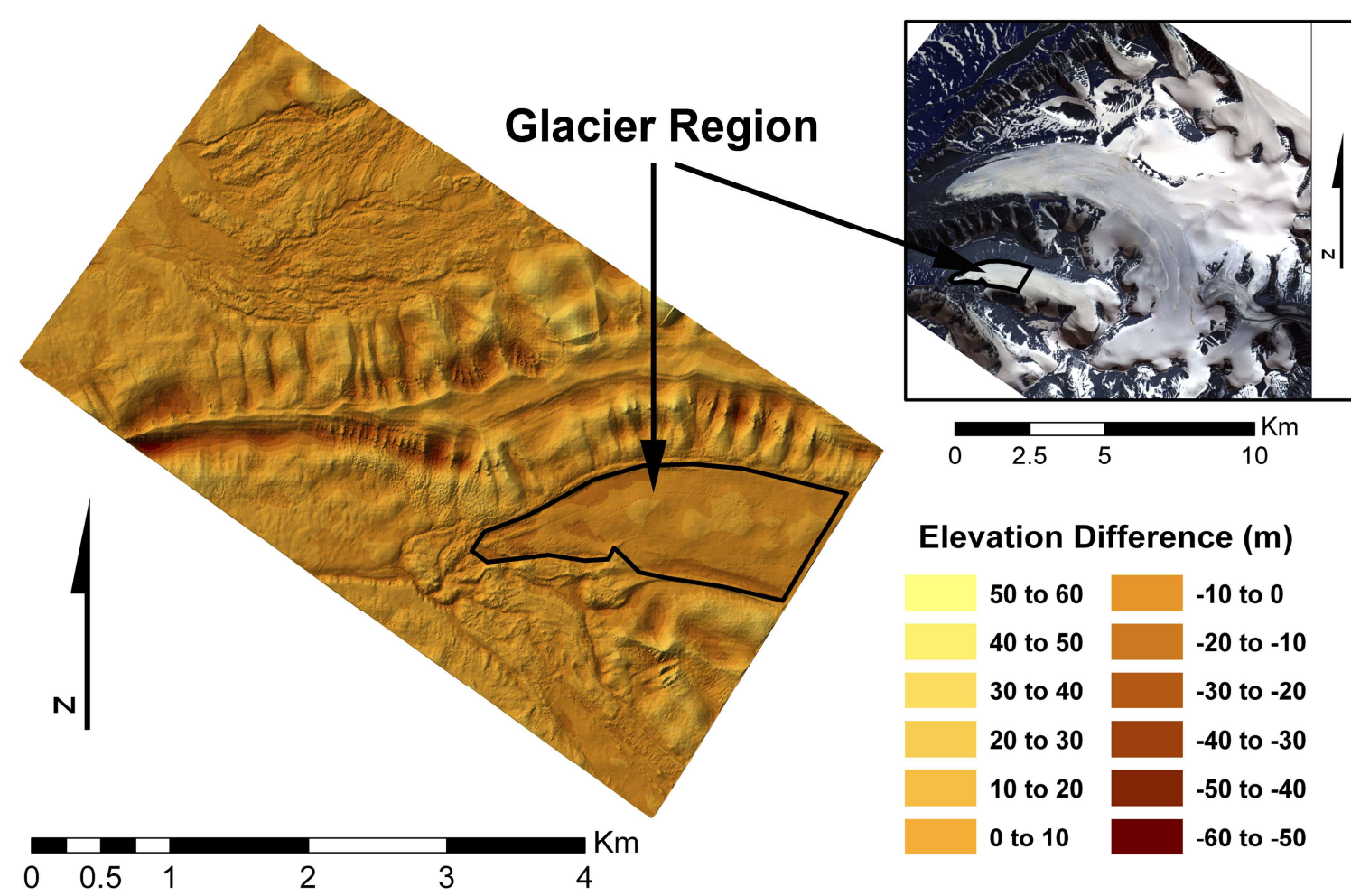

Fig. 3. Elevation differences; post-match 2003 photogrammetric DEM minus 2002 ASTER DEM. Glacier margin highlighted.

As highlighted in Fig. 3, marked negative changes were observed over the glacier region. LSS was used to determine volumetric change between the original ASTER DEM and the matched photogrammetric DEM, and between the lidar DEM and the matched ASTER DEM, for the glacier region only. The results are presented in Table IV. The values derived from the two matching strategies differ by around $50,000 \mathrm{~m}^{3}$, which equates to an error of $0.63 \%$, as calculated from the ASTERto-lidar matching. In terms of elevation change across the glacier area as a whole, this represents an average elevation difference of only $3 \mathrm{~cm}$ and indicates encouragingly strong agreement between the two matching strategies.

TABLE IV

ANALYSIS OF VOLUMETRIC CHANGE FOR GLACIER REGION

\begin{tabular}{rrr}
\hline \hline Matching Strategy & \multicolumn{1}{c}{$\begin{array}{c}\text { Photo to } \\
\text { ASTER }\end{array}$} & $\begin{array}{c}\text { ASTER to } \\
\text { lidar }\end{array}$ \\
\hline Surface Area $\left(\mathrm{m}^{2}\right)$ & $1,499,325.86$ & $1,494,077.44$ \\
Gain $\left(\mathrm{m}^{3}\right)$ & $289,931.02$ & $255,908.80$ \\
Loss $\left(\mathrm{m}^{3}\right)$ & $-8,292,605.14$ & $-8,208,785.76$ \\
Net change $\left(\mathrm{m}^{3}\right)$ & $-8,002,674.12$ & $-7,952,876.96$ \\
\hline Difference $\left(\mathrm{m}^{3}\right)$ & \multicolumn{2}{c}{$49,797.16$} \\
Difference $(\%)$ & 0.63 \\
\hline \hline
\end{tabular}

In total, there has been a net volumetric loss of 8 million $\mathrm{m}^{3}$ over an area of 1.5 million $\mathrm{m}^{2}$. This is a relatively large change for a 14 month period, and it is important to highlight that the matching and analysis was carried out over a relatively small part of the glacier system. Following this, estimations of mean annual elevation change (water equivalent) were calculated for the glacier front. The calculations are based on the following relationship:

Mean elevation change rate $=\frac{\left(\text { Vol }_{\text {diff }} \times \rho\right)}{\text { Area }} \times \frac{12}{t_{\text {diff }}}$

Where $V_{\text {ol }}$ iff is the volumetric change in $\mathrm{m}^{3}$;

$\rho \quad=0.9$, is the density correction factor;

Area is the total surface area in $\mathrm{m}^{2}$;

$t_{\text {diff }} \quad$ is the time difference in months.

For the highlighted glacier region (Fig. 3), the mean annual elevation change rate for June 2002-August 2003 is approximately $-4.12 \mathrm{ma}^{-1}$ (-4.11 $\mathrm{ma}^{-1}$ for lidar-based matching; $0.24 \%$ difference). This elevation change rate compares favourably with results from other studies (e.g. [42]).

\section{Discussion}

The results presented here have demonstrated the potential of surface matching as a technique for facilitating accurate glacier change analysis. It has been shown that ASTER DEMs are 
capable of providing a reference surface for accurate scaling of photogrammetric DEMs. This offers tremendous potential for greater exploitation of archival aerial photography, as well as DEMs derived from other sources.

A growing number of studies are applying remote sensing imagery to the critical issue of glacier mass balance [e.g. 43]. Airborne and satellite-based remote sensing offer the most effective means of assessing mass balance, particularly over regional extents [44]. However, [45] also comment that the requirement for ground control is currently a major limiting factor, particularly in relation to greater exploitation of photogrammetric data. The technique presented here provides an efficient means of overcoming this problem. Furthermore, while this research does not directly estimate glacier mass balance, the strategy supplies a reliable and effective mechanism for doing so. As a result, this approach offers a novel and flexible methodology for glacier change assessment, with implications for climate change analysis. As glaciated regions are generally considered as being particularly sensitive to the effects of climate change, continued assessment and retrospective analysis of change is essential.

The ASTER-based surface matching strategy offers several key advantages over existing approaches to glacial change assessment. Foremost, this approach removes the requirement for establishing ground control, which has thus far been a significant limiting factor in many image-based change detection studies. In addition, DEMs facilitate detailed examination of specific features, and the continuous spatial nature of this data source supports analysis which is superior to approaches reliant on point samples or transect data alone [45]. Finally, the use of ASTER data enables this technique to be applied over near-global extents. Where suitable historical DEMs are unavailable for comparison, multi-temporal ASTER datasets (or DEMs derived from other spaceborne sensors) can be used for analysis of more recent change. These may also benefit from the outlined surface matching approach.

A number of specific points can be highlighted in relation to the performance of the surface matching algorithm. It is an advantage of the algorithm that not all points are required to achieve an optimum solution; testing has shown that it is possible to reduce the spatial resolution of the surfaces without compromising the quality of the solution. The final transformation parameters can then be applied to the complete dataset, and subsequent analysis carried out at full resolution. However, matching must be performed over the entire area of interest - it is not advisable to match only a small subset of the DEM and then apply the solution to a wider extent. In this case, it has been found that the quality of the solution will deteriorate as distance from the matched area increases. In order to match over large extents, as may be necessary when analysing entire glacier systems, the performance of the software requires improvement through the implementation of spatial indexing strategies, such as an octree-based approach (e.g. [46]). This would allow the point correspondence search time to be reduced, thus increasing the capacity of the algorithm to handle larger datasets.

While pseudo-control points extracted from the lidar DEM were used here to approximately orient the photogrammetric model prior to matching, this does not limit the wider applicability of this technique. Control points derived from large scale topographic mapping would have been equally effective in this respect.

Prior to applying this technique over wider extents, it would be desirable to carry out a robust assessment of the accuracy of the matching solutions, using GPS check points acquired in the field. This would also allow for an investigation of the errors associated with the differing spatial resolutions of the ASTER, lidar and photogrammetric DEMs. Ultimately, errors introduced by the relatively low spatial resolution of the ASTER DEM $(30 \mathrm{~m})$ are likely to limit the accuracy of the results. In addition, the approach proposed here is entirely image-based, and it is important to acknowledge that image matching problems may affect the quality of the DEMs. Furthermore, the challenges associated with successful photogrammetric processing of archival imagery should not be overlooked. However, notwithstanding these factors, the results presented here have demonstrated that this technique is capable of facilitating accurate volumetric change analysis of glaciated terrain. Indeed, without application of translation and rotation parameters, biased volume change measurements would have resulted.

The ASTER DEM supplied by LP DAAC is produced without the use of ground control points, instead relying on the sensor's ephemeris and attitude data. The consistent quality of this should ensure that the scale-stability of the ASTER DEM is maintained on a global basis. In terms of overall volumetric change, the ASTER-based matching technique was found to be accurate to within $0.6 \%$ of the lidar-based solution. This performance is highly encouraging, and importantly, suggests that this approach should remain comparatively sensitive to the detection of low-magnitude trends.

Although this study analysed glacier change over a relatively short period of 14 months, the datasets were acquired at similar times of year (June 2002 and August 2003), therefore minimising changes which could be attributed to seasonally-induced snow accumulation or melting. The results provide a strong indication that the glacier is losing mass, and present a compelling case for continued monitoring of this region. Future work will involve further verification of the approach presented here. This will include assessing the matching strategy using ASTER DEMs for different regions of Earth's surface, including regions of steeper topography. In addition, testing will be carried out in order to establish the accuracy and limitations of the technique for surfaces which are primarily composed of snow or ice, and to examine how the spatial distribution of stable terrain influences the quality of the solution. While the predominance of ice-covered terrain would not necessarily preclude the application of surface matching, it is essential that potentially unstable or dynamic areas are down-weighted through the robust features of the 
algorithm. In the longer-term, efforts will be concentrated on implementing this strategy in order to extract change information from archival aerial photography stretching back over several decades. This will lead to an improved understanding of glacier behaviour in response to climate change, and will involve further analysis of the Svalbard archipelago.

\section{CONCLUSION}

This paper presents a novel solution for the reliable determination of volumetric change in glacial environments. At the core of the strategy lies a least squares-based surface matching algorithm, facilitating the robust registration of multi-sensor, multi-temporal DEMs. Focussing on part of the Slakbreen glacier system on Spitsbergen, Svalbard, this paper has demonstrated that ASTER DEMs are essentially correct in scale. This property underpins their value as a reference DEM for surface matching, thus providing an automated solution for scaling of archival photogrammetric datasets. Crucially this approach removes the requirement for ground control, and supplies an effective mechanism for dataset registration and volumetric change assessment. Results suggest that the ASTER-based matching approach is capable of determining volumetric change to within $0.6 \%$ of a truth dataset. For the glacier region analysed over the 14 month study period, there was a net volumetric loss of 8 million $\mathrm{m}^{3}$ over an area of 1.5 million $\mathrm{m}^{2}$, providing a strong indication of glacier mass loss. Given the near-global coverage of ASTER data, and the relatively extensive archives of aerial photography which exist for many glaciated regions, this technique has the potential to make a significant and timely contribution to change analysis in climatically-sensitive environments.

\section{ACKNOWLEDGMENT}

The authors would like to acknowledge the UK Natural Environment Research Council's Airborne Research and Survey Facility (NERC ARSF) for acquisition and processing of lidar data and aerial imagery used in this research. The datasets were obtained as part of the NERC-funded SLICES project, based at Swansea University (NE/B505203/1). The reported research was part-funded under a NERC standard grant (J.P.M., M.A.K., T.M, and T.D.J.) and a NERC fellowship (M.A.K.).

\section{REFERENCES}

[1] M. F. Meier., M.B. Dyurgerov, U.K. Rick, S. O'Neel, W.T. Pfeffer, R.S Anderson, S.P. Anderson, and A.F. Glazovsky, "Glaciers dominate Eustatic sea-level rise in the 21 st century," Science, vol 317, no. 5841, pp. 1064-1067, 2007.

[2] S. J. S. Khalsa, M.B. Dyurgerov, T. Khromova, B.H. Raup, and R.G. Barry, "Space-based mapping of glacier changes using ASTER and GIS tools," IEEE Transactions on Geoscience and Remote Sensing, vol. 42 no. 10 , pp. 2177-2183, 2004.
[3] T. D. James, T. Murray, N.E. Barrand, and S.L. Barr, "Extracting photogrammetric ground control from lidar DEMs for change detection," Photogrammetric Record, vol. 21 no. 116, pp. 312-328, 2006.

[4] Fox, A.J. and Cziferszky, A., "Unlocking the time capsule of historical aerial photography to measure change in Antarctic Peninsula glaciers," Photogrammetric Record, vol. 23, no. 121, pp. 51-68, 2008.

[5] B. Raup, A. Kaab, J.S. Kargel, M.P. Bishop, G. Hamilton, E. Lee, F. Paul, F. Rau, D. Soltesz, S.J.S. Khalsa, M. Beedle, and C. Helm, "Remote sensing and GIS technology in the global land ice measurements from space (GLIMS) project," Computers \& Geosciences, vol 33 no. 1, pp. 104-125, 2007.

[6] A. B. Surazakov, and V.B. Aizen, "Estimating volume change of mountain glaciers using SRTM and map-based topographic data," IEEE Transactions on Geoscience and Remote Sensing, vol. 44 no. 10, pp. 2991-2995, 2006.

[7] L. A. Stearns, and G.S. Hamilton, "Rapid volume loss from two East Greenland outlet glaciers quantified using repeat stereo satellite imagery," Geophysical Research Letters, vol. 34, L05503, doi:10.1029/2006GL028982, 2007.

[8] I. M. Howat, I. Joughin, and T.A. Scambos, "Rapid changes in ice discharge from Greenland outlet glaciers," Science, vol. 315 no. 5818 , pp. 1559-1561, 2007.

[9] E. Y. Berthier, Arnaud, C. Vincent, and F. Remy, "Biases of SRTM in high-mountain areas: Implications for the monitoring of glacier volume changes," Geophysical Research Letters, vol. 33 L08502, doi: 10.1029/2006GL025862, 2006.

[10] J. L. Bamber, W. Krabill, V. Raper, J. A. Dowdeswell and J. Oerlemans, "Elevation changes measured on Svalbard glaciers and ice caps from airborne laser data," Ann. of Glaciology, vol. 42, no. 1, pp. 202-208, 2005.

[11] Ø. Nordli, "Long-term temperature trends and variability at Svalbard (1911-2004)," Geophysical Research Abstracts, vol. 7, no. 06939, 2005.

[12] H. Fujisada, G. B. Bailey, G. B. Kelly, G. G. Hara and M. J. Abrams, "ASTER DEM performance," IEEE Transactions on Geoscience and Remote Sensing, vol. 42, no. 12, pp 2707-2714, 2005.

[13] A. Cuartero, A. M. Felicísimo, F. J. Ariza, "Accuracy, reliability, and depuration of SPOT HRV and Terra ASTER digital elevation models," IEEE Transactions on Geoscience and Remote Sensing, vol. 42, no. 2, pp. 404-407, 2005.

[14] M. P. Baltsavias, E. Favey, A. Bauder, H. Bösch and M. Pateraki, "Digital surface modelling by airborne laser scanning and digital photogrammetry for glacier monitoring," Photogrammetric Record, vol. 17 , no. 98 , pp. 243-273, 2001.

[15] A. Hirano, R. Welch and H. Lang, "Mapping from ASTER stereo image data: DEM validation and accuracy assessment," ISPRS J. Photogrammetry and Remote Sensing, vol. 57, no. 5-6, pp. 356-370, 2003.

[16] T. Bolch, U. Kamp and J. Olsenholler, "Using ASTER and SRTM DEMs for studying geomorphology and glaciation in high mountain areas," in Proc. $24^{\text {th }}$ EARSeL Symp.: New Strategies for European Remote Sensing, Dubrovnik, Croatia, 2004

[17] I. G. Fourniadis, J. G. Liu and P. J. Mason, "Landslide hazard assessment in the Three Gorges area, China, using ASTER imagery: Wushan-Badong," Geomorphology, vol. 84, no. 1-2, pp. 126-144, 2007.

[18] A. Kääb, "Combination of SRTM3 and repeat ASTER data for deriving alpine flow velocities in the Bhutan Himalaya," Remote Sensing of the Environment, vol. 94, no. 4, pp. 463-474, 2005.

[19] A. Kääb, "Glacier volume changes using ASTER satellite stereo and ICESat GLAS laser altimetry. A test study on Edgeøya, Eastern Svalbard," IEEE Transactions on Geoscience and Remote Sensing, vol. 46, no. 10 , pp. 2823-2830, 2008.

[20] LP DAAC. (2006, June). ASTER Digital Elevation Model [Online]. Available: http://edcdaac.usgs.gov/aster/ast14dem.asp

[21] M. Flood, "LIDAR activities and research priorities in the commercial sector," International Archives of Photogrammetry, Remote Sensing and Spatial Information Sciences, vol. 34, no. 3/W4, pp. 3-7, 2001.

[22] R. Würländer, K. Eder and T. Geist, "High quality DEMs for glacier monitoring - image matching versus laser scanning" International 
Archives of Photogrammetry, Remote Sensing and Spatial Information Sciences, vol. 35, no. B7, pp. 753-758, 2004.

[23] NERC ARSF. (2005, December). The Optech Airborne Laser Terrain Mapper 3033 [Online]. Available: http://arsf.nerc.ac.uk/instruments/altm.asp

[24] M. A. King, "The GPS contribution to the error budget of surface elevations derived from airborne LIDAR," IEEE Transactions on Geoscience and Remote Sensing, to be published.

[25] E. Brückl, F. K. Brunner and K. Kraus, "Kinematics of a deep-seated landslide derived from photogrammetric, GPS and geophysical data," Engineering Geology, vol. 88, no. 3-4, pp. 149-159, 2006.

[26] E. Schiefer and R. Gilbert, "Reconstructing morphometric change in a proglacial landscape using historical aerial photography and automated DEM generation," Geomorphology, vol. 88, no. 1-2, pp. 167-178, 2007.

[27] BAE Systems, SOCET SET User's Manual Version 5.4.1, 1134 pages, 2007.

[28] T. Schenk and B. Csathó, "Fusion of LiDAR data and aerial imagery for a more complete surface description," International Archives of Photogrammetry, Remote Sensing and Spatial Information Sciences, vol. 34, no. 3A, pp. 310-317, 2002.

[29] P. E. Miller, J. P. Mills, S. J. Edwards, P. Bryan, S. Marsh, H. L. Mitchell and P. Hobbs, "A robust surface matching technique for coastal geohazard assessment and management," ISPRS J. Photogrammetry and Remote Sensing, vol. 63, no. 5, pp. 529-542, 2008.

[30] P. R. Wolf and B. A. Dewitt, Elements of Photogrammetry with Applications in GIS. New York: McGraw-Hill, 2000, 608 pages.

[31] J. P. Mills, S. J. Buckley and H. L. Mitchell, "Synergistic fusion of GPS and photogrammetrically generated elevation models,"

Photogrammetric Engineering and Remote Sensing, vol. 69, no. 4, pp. 341-349, 2003.

[32] H. L. Mitchell and R. G. Chadwick, "Digital photogrammetric concepts applied to surface deformation studies," Geomatica, vol. 53, no. 4, pp. 243-257, 1999.

[33] J. P. Mills, S. J. Buckley, H. L. Mitchell, P. J. Clarke and S. J. Edwards, "A Geomatics data integration technique for coastal change monitoring," Earth Surface Processes and Landforms, vol. 30, no. 6, pp. 651-664, 2005.

[34] Z. Li, Z. Xu, M. Cen and X. Ding, "Robust surface matching for automated detection of local deformations using Least-Median-of Squares estimator," Photogrammetric Engineering and Remote Sensing, vol. 67, no. 11, pp. 1283-1292, 2001.

[35] N. R. Draper and H. Smith, Applied Regression Analysis. New York: Wiley, 1998, 706 pages.

[36] L. J. Pilgrim, "Robust estimation applied to surface matching," ISPRS J. Photogrammetry and Remote Sensing, vol. 51, no. 5, pp. 243-257, 1996.

[37] P. E. Miller, J. P. Mills, S. J. Edwards, P. Bryan, S. Marsh, P. Hobbs and H. L. Mitchell, "A robust surface matching technique for integrated monitoring of coastal geohazards," Marine Geodesy, vol. 30, no. 1-2, pp. 109-123, 2007.

[38] Terrasolid, TerraScan User's Guide, 169 pages, 2005.

[39] McCarthy Taylor, LSS v9.60 Help Manual, 2007.

[40] ESRI, Arc GIS v9.2 Desktop Help Manual, Environmental Systems Research Institute, 2006.

[41] R. Paquet, "A method to predict accuracy of least squares surface matching for airborne laser scanning datasets," International Archives of Photogrammetry, Remote Sensing and Spatial Information Sciences, vol 34, no. 3/W13, 6 pages, 2003

[42] J. Kohler, T. J. James, T. Murray, C. Nuth, O. Brandt, N. E. Barrand, H. F. Aas and A. Luckman, "Acceleration in thinning rate in western Svalbard glaciers," Geophysical Research Letters, vol. 34, no. L18502, 2007.

[43] E. Berthier, Y. Arnaud, R. Kumar, S. Ahmad, P. Wagnon and P. Chevallier, "Remote sensing estimates of glacier mass balance in the Himachal Pradesh (Western Himalaya, India)," Remote Sensing of the Environment, vol. 108, no. 3, pp. 327-338, 2006

[44] J. L. Bamber and A. Rivera, "A review of remote sensing methods for glacier mass balance determination," Global and Planetary Change, vol. 59, no. 1-4, pp. 138-148, 2007.
[45] I.M. Howat, B.E. Smith, I. Joughin, and T.A. Scambos, "Rates of southeast Greenland ice volume loss from combined ICESat and ASTER observations," Geophysical Research Letters, vol. 35, no. L17505, 2008 .

[46] D. M. Barber, D. Holland and J. P. Mills, "Change detection for topographic mapping using three-dimensional data structures," International Archives of Photogrammetry, Remote Sensing and Spatial Information Sciences, vol. 37, no. B4, pp. 1177-1182, 2008.

Pauline E. Miller obtained a BSc (Hons.) in Topographic Science from the University of Glasgow, UK in 2001, and a PhD in Geomatics from Newcastle University in 2007, where she currently works as a Research Associate in the School of Civil Engineering and Geosciences. Her main research interests relate to data integration and least squares surface matching for geohazard applications.

Matthias Kunz is a doctoral student at Newcastle University. He holds a Diploma in Geography from the Technical University Dresden (2008), and has recently completed an internship at GFZ Potsdam. The research presented here was undertaken during an ERASMUS placement at Newcastle University. His current research focusses on improving the robustness of earth observation assessment of geohazards and environmental change in challenging environments.

Jon P. Mills is Professor of Geomatic Engineering in the School of Civil Engineering and Geosciences at Newcastle University. He is a professionally qualified Chartered Surveyor and holds a BSc (Hons.) degree in Surveying Science and a PhD in Digital Photogrammetry.

Matt A. King received B. Surv. (Hons.) and $\mathrm{PhD}$ degrees at the University of Tasmania, Australia, in 1997 and 2002, respectively. He is currently a NERC (UK) research fellow in the geodesy group at Newcastle University (UK) where he focuses on application of GPS and other geodetic techniques to problems mainly relating to polar geodesy, glaciology and tides.

Tavi Murray is Professor of Glaciology in the School of the Environment and Society at Swansea University. She received a BSc in Physics and Computer Science (1987) and a PhD in Glacier Geophysics (1990) from the University of Wales. Her research interests focus on glacier dynamics and the contribution of glaciers and ice sheets to sea-level rise

Timothy D. James received a BSc (Hons.) degree from Queen's University in Canada in 1996, an M.Phil in GIS and Remote Sensing from the University of Cambridge in 1997 and his Ph.D. from the University of Leeds in 2003. His research interests include the quantification of historical changes in glaciers and ice sheets which he has pursued first as a postdoctoral researcher on the NERC-funded SLICES project and now as the project manager for the GLIMPSE project at Swansea University.

Stuart H. Marsh received a BSc (Hons.) in Geological Sciences from Birmingham University in 1988 and a PhD in Geological Remote Sensing from Durham University in 1993. He has been with the British Geological Survey since 1991, where he is currently Head of Spatial Geoscience Technologies. 